\title{
A direct method for the vulcanization of acrylate rubber through in situ coordination crosslinking
}

\author{
Haiyan Mou, Pengfei Xue, Qingfeng Shi, Weihong Guo, Chifei Wu and Xiaowei Fu \\ In this work, a straightforward method of vulcanizing acrylate rubber (AR) was explored via the introduction of in situ \\ coordination crosslinking. An inorganic metal salt, copper sulfate $\left(\mathrm{CuSO}_{4}\right)$, was mechanically mixed with AR and heat pressed \\ to prepare a novel crosslinkable $\mathrm{AR} / \mathrm{CuSO}_{4}$ composite. The determination of the coordination bonding between the ester groups \\ of AR and copper (II) ions was performed with Fourier transform infrared spectroscopy based on the red shifts of the ester \\ group absorption bands and the disappearance of the coordinated sulfate absorption bands, as well as by electron spin \\ resonance based on the changes in the g-factor of copper (II). The crosslinking procedure of the composite was investigated \\ through dynamic mechanical analysis. In addition, the extent of the crosslinking of the AR/CuSO ${ }_{4}$ composites was evaluated by \\ observing the swelling behaviors. Scanning electron microscopy was used to investigate the morphology of the composite. The \\ vulcanizates exhibited improved physical properties with high elongation at break due to exchange reaction between the ester \\ groups of $\mathrm{AR}$ and $\mathrm{CuSO}_{4}$.
}

Polymer Journal (2012) 44, 1064-1069; doi:10.1038/pj.2012.59; published online 25 April 2012

Keywords: acrylate rubber; coordination; polymer composites; vulcanization

\section{INTRODUCTION}

Acrylate rubbers (AR) exhibit the favorable qualities of weatherability, high temperature serviceability and good oil resistance. These qualities make the rubbers useful for under-the-hood automotive applications and outdoor applications. However, because AR is a saturated rubber, it is impossible for it to be vulcanized through traditional sulfur-vulcanizing systems like unsaturated rubbers. A considerable amount of research has been accomplished in the past years to introduce various types of active cure-site monomers into AR chains during the polymerization process. The most common curesite monomers include those containing a labile halogen atom, a carboxyl group, an epoxide moiety, an unsaturated double bond, and a combination of two or more monomers resulting in dual or multiple cure sites, which require different curing systems as shown in Table 1. Despite significant advances in cure technology, all of the current acrylic elastomers require a relatively long cure cycle or must be post-cured.

In this work, we aimed to develop a straightforward method to vulcanize AR by introducing coordination-bond crosslinking. Ester carbonyl is capable of coordinating with metal ions, especially in solution systems. Metal complexes with carboxylic esters as ligands have long been in practice. A brief overview of low-molecular-weight organic compound complexes that contain coordinated ester groups was presented by Schreiner et al. ${ }^{20}$ Multidentate ligands containing esters and other functional groups have been recently attracting the attention of researchers because of their various coordination modes that are controlled by the subtle interplay between stereo-electronic factors. Attempts ${ }^{21-24}$ at such studies also revealed the coordination behaviors involving both the carbonylic and the alkoxy atoms of esters with metal ions. Moreover, regarding ester-containing polymers, Rolker et al. ${ }^{25}$ observed that their viscosity was increased when they were treated with iron, cobalt or nickel carbonyl complexes at elevated temperatures in nitrogen. Nunnery et al. ${ }^{26}$ considered this phenomenon and suggested the formation of a weak metal-COOR bond, where the inorganic species serve as weakly bonded bridges between the polymer chains, thereby promoting a rise in viscosity. Accordingly, ARs are prospective ligands for forming coordination crosslink structures upon the coordination of the polar ester lateral groups with metal ions. To our knowledge, however, there is little information available in the literature about the vulcanization of AR through coordination crosslinking. In this work, copper sulfate $\left(\mathrm{CuSO}_{4}\right)$ was used as a curing ingredient to vulcanize $\mathrm{AR}$ by a simple two-step process, including milling and heat press. It is expected that the issue involving the avoidance of introducing curesite monomers and optimizing the corresponding curing system, the long-time cure circle and the post-cure process will be resolved with our proposed method.

We preliminarily focused on the coordination reaction, structure and properties of an $\mathrm{AR} / \mathrm{CuSO}_{4}$ composite in this paper. The coordination reaction between the ester lateral groups and the copper 
(II) ions was investigated by Fourier transform-infrared spectrometry (FT-IR), ESR, and dynamic mechanical analysis(DMA). The extent of the crosslinking of the $\mathrm{AR} / \mathrm{CuSO}_{4}$ composites was measured with a swell equilibrium method. The morphology and the mechanical properties of the novel $\mathrm{AR} / \mathrm{CuSO}_{4}$ composite were investigated by an scanning electron microscope (SEM) and a tensile test.

\section{EXPERIMENTAL PROCEDURE}

\section{Materials and preparation}

The AR used in this work was supplied by Zeon Inc. (Kawasaki, Japan) under the trade name AR42w, which contains an epoxy cure site with a Mooney viscosity of 33.5. $\mathrm{CuSO}_{4}$ was purchased from the Shanghai Zhenxin chemical reagent factory (Shanghai, China).

The blending of the AR and the $\mathrm{CuSO}_{4}$ was implemented in an open tworoll mill at room temperature. After mixing, the compound was discharged and compression molded into 1-mm-thick plates at a series of temperatures, including 150,180 and $210^{\circ} \mathrm{C}$, for $20 \mathrm{~min}$.

\section{Characterization}

Infrared spectra were obtained using a Bruker EQUNOX55 Fourier transform infrared spectrometer. The scanned wave number ranged from $4000 \mathrm{~cm}^{-1}$ to $400 \mathrm{~cm}^{-1}$. The spectral resolution was $2 \mathrm{~cm}^{-1}$. The samples were pressed into a film in a heat press at elevated temperatures for $20 \mathrm{~min}$ and were then cooled to room temperature. The thickness of the film sample for the FT-IR measurement was approximately $20 \mu \mathrm{m}$.

The ESR spectra were obtained with an X-band $(9.86 \mathrm{GHz})$ ESR spectrometer (Bruker Biospin GMBH, Rheinstetten, Germany, Type EMX-8/2.7) at room temperature. The $\mathrm{AR} / \mathrm{CuSO}_{4}$ composite was ground to pellets before testing.

DMA was performed with a UBM Rheogel E4000 dynamic mechanical analyzer. Samples were cold pressed until flat and cut into small, thin sheets of $4 \times 4 \times 1 \mathrm{~mm}^{3}$ for DMA testing. In the non-isothermal experiment, the test temperature ranged from -30 to $300^{\circ} \mathrm{C}$. The heating rate of the temperature scan was $3{ }^{\circ} \mathrm{C}$ per min. In the isothermal experiment, the samples were tested

Table 1 Species of cure-site monomers and their corresponding curing systems of acrylate rubbers

\begin{tabular}{|c|c|}
\hline Cure-site monomers & Curing systems \\
\hline \multirow[t]{3}{*}{ Halogen groups } & Soap-sulfur or peroxide ${ }^{1,2}$ \\
\hline & Trithiocyanuric acid and calcium hydroxide ${ }^{3}$ \\
\hline & Aliphatic polyamines 4 \\
\hline \multirow[t]{3}{*}{ Carboxyl groups } & Quaternary ammonium salts 5,6 \\
\hline & Hexamethylenediaminecarbamate and \\
\hline & $\mathrm{N}, \mathrm{N}^{\prime}$-diorthotolylguanidine coagent ${ }^{7}$ \\
\hline \multirow[t]{4}{*}{ Epoxide groups ${ }^{8}$} & Quaternary ammonium salts \\
\hline & An isocyanuric acid and a quaternary \\
\hline & ammonium salt ${ }^{9}$ \\
\hline & UV10 \\
\hline Unsaturated double & Sulfur or peroxide \\
\hline
\end{tabular}

bonds $^{11}$

Carboxyl groups and chlorine groups ${ }^{12}$

Carboxyl and epoxide groups

Aliphatic

diaminecarboxylate ${ }^{19}$ for $100 \mathrm{~min}$ at setting temperatures. The average strain was $0.05 \%$ at a frequency of $11 \mathrm{~Hz}$.

The extent of the crosslinking of the heat-pressed $\mathrm{AR} / \mathrm{CuSO}_{4}$ samples was evaluated by their swelling behaviors using ethyl acetate as a solvent at room temperature for an immersion period of 8 days. Each sample was cut into a size of $10 \times 10 \times 1 \mathrm{~mm}^{3}$ in advance. The swelling index of the samples was calculated by the following equation:

$$
Q=\frac{M_{t}-M_{0}}{M_{0}}
$$

where $Q$ is the swelling index of the sample, $M_{0}$ is the mass of the initial sample, and $M_{t}$ isthe mass of the swollen sample.

Tensile tests were carried out in a Shimadzu AG-2000A (Shimadzu, Tokyo, Japan) at room temperature with a grip separation rate of $200 \mathrm{~mm}$ per $\mathrm{min}$ using dumbbell specimens with $1 \mathrm{~mm}$ thicknesses.

The morphologies of the fractured surfaces of the samples were examined on a JEOL JSM-6360 SEM (JEOL, Tokyo, Japan). The samples were fractured before hand in liquid nitrogen and coated with a thin layer of gold.

\section{RESULTS AND DISCUSSION}

\section{Coordination-bonded networks}

Figure 1 shows the FT-IR spectra of the $\mathrm{CuSO}_{4}, \mathrm{AR}$, and $\mathrm{AR} / \mathrm{CuSO}{ }_{4}$ composites before and after heat pressing. The characteristic absorption peaks of the $\mathrm{CuSO}_{4}$ powder appeared to be $1206 \mathrm{~cm}^{-1}$, $1174 \mathrm{~cm}^{-1}, \quad 1100 \mathrm{~cm}^{-1}$ and $1047 \mathrm{~cm}^{-1}\left(v_{3}\left(\mathrm{SO}_{4}\right)\right), \quad 992 \mathrm{~cm}^{-1}$ $\left(v_{1}\left(\mathrm{SO}_{4}\right)\right), \quad 776 \mathrm{~cm}^{-1}, \quad 641 \mathrm{~cm}^{-1}$ and $605 \mathrm{~cm}^{-1}\left(v_{4}\left(\mathrm{SO}_{4}\right)\right)$, and $472 \mathrm{~cm}^{-1}\left(v_{2}\left(\mathrm{SO}_{4}\right)\right)\left(v_{1}, v_{2}, v_{3}\right.$ and $v_{4}$ correspond to four types of normal vibrations of sulfate). This result indicated that sulfate acted as a typical bidentate ligand. ${ }^{27}$ The absorption bands at $674 \mathrm{~cm}^{-1}$, $630 \mathrm{~cm}^{-1}$ and $595 \mathrm{~cm}^{-1}$ can be attributed to the coordinated sulfate in the spectra of the $\mathrm{AR} / \mathrm{CuSO}_{4}$ composites before heat pressing, which nearly disappeared following the heat pressing. It can be inferred that, when blended with $\mathrm{AR}$, the coordination structure of the $\mathrm{CuSO}_{4}$ changed, and after heat pressing, the sulfate contributed insignificantly to the coordination.

AR featured a $\mathrm{C}=\mathrm{O}$ stretching band $(v(\mathrm{C}=\mathrm{O}))$ at $1735 \mathrm{~cm}^{-1}$, an asymmetrical stretching mode $\left(v_{a}(\mathrm{C}-\mathrm{O}-\mathrm{R})\right)$ at $1254 \mathrm{~cm}^{-1}$ and a symmetrical stretching mode $\left(v_{s}(\mathrm{C}-\mathrm{O}-\mathrm{R})\right)$ at $1163 \mathrm{~cm}^{-1}$, in addition to an epoxide group stretching band at $857 \mathrm{~cm}^{-1}$ and a symmetrical stretching band at $957 \mathrm{~cm}^{-1}$. The epoxide groups of the $\mathrm{AR} / \mathrm{CuSO}_{4}$ composites before and after heat pressing had insignificantly changed compared with those of the AR. This finding indicated that no coordination reaction occurred between the epoxide groups and the copper ions. In contrast, the ester group absorption bands of AR/ $\mathrm{CuSO}_{4}$ after heat pressing indicated obvious red shifts (listed in Table 2). The decreased carbonyl stretching frequency has proven to be an easy and accurate diagnosis for the coordinationof the ester

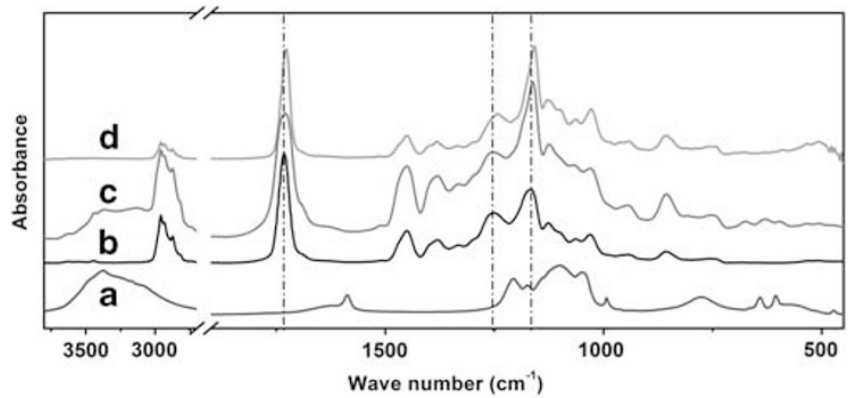

Figure 1 FT-IR spectra of $\mathrm{CuSO}_{4}(\mathrm{a}), \mathrm{AR}$ (b), and $\mathrm{AR} / \mathrm{CuSO}_{4}$ composites before (c) and after (d) heat pressing. A full color version of this figure is available at Polymer Journal online. 
groups. By examining the wave number shifts in the bands for $v(\mathrm{C}=\mathrm{O}), v_{a}(\mathrm{C}-\mathrm{O}-\mathrm{R})$ and $v_{s}(\mathrm{C}-\mathrm{O}-\mathrm{R})$, the nature of the complex formation between the metal cations and the ester groups can be determined. It has been recognized since 1958 that the coordination of one oxygen atom of the ester carbonyl group leads to a remarkable decrease in the carbonyl stretching frequency and to an increase in the frequency of the C-O-R vibration. ${ }^{28}$ Hull et al. ${ }^{29}$ demonstrated that the coordination of both of the oxygen atoms of the ester group caused a decrease in the characteristic frequencies for all three of the vibration bands of the ester. In this case, both of the oxygen atoms of the ester group participated in the coordination with the copper ions because all three of the absorption bands of the ester group shifted to low wave numbers.

$\mathrm{X}$-band EPR spectroscopy was used to gain further insight into the coordination sphere of $\mathrm{Cu}^{2+}$ in the complexes with AR. The ESR spectra of the powdered $\mathrm{CuSO}_{4}$ and the $\mathrm{AR} / \mathrm{CuSO}_{4}$ composite (Figure 2) exhibited anisotropic spectra with intense broad signals and no hyperfine structure at room temperature.

The g-Tensor values have been determined with the Knübuhl method. ${ }^{30}$ The $g_{\|}$value provides information about the types of donor atom complexes with copper (II) and the strength of their interactions. ${ }^{31}$ Regarding the oxygen atoms from the two ligands, the strength of the interaction between the atoms and the copper (II)ions decreased with decreasing $g_{\|}$values in the following order: sulfate

Table 2 Characteristic IR absorptions $\left(\mathrm{cm}^{-1}\right)$ of the ester group of the $\mathrm{AR}$ and $\mathrm{AR} / \mathrm{CuSO}{ }_{4}$ composites before and after heat pressing

\begin{tabular}{|c|c|c|c|c|c|c|}
\hline & \multicolumn{2}{|c|}{$v(C=0)$} & \multicolumn{2}{|c|}{$v_{a}(C-O-R)$} & \multicolumn{2}{|c|}{$v_{s}(C-O-R)$} \\
\hline & Peak & $\begin{array}{l}\text { Red- } \\
\text { shift }\end{array}$ & Peak & $\begin{array}{l}\text { Red- } \\
\text { shift }\end{array}$ & Peak & $\begin{array}{l}\text { Red- } \\
\text { shift }\end{array}$ \\
\hline Raw AR & 1735 & & 1254 & & 1163 & \\
\hline $\begin{array}{l}\mathrm{AR} / \mathrm{CuSO}_{4} \text { before heat } \\
\text { pressing }\end{array}$ & 1733 & -2 & 1254 & & 1160 & -3 \\
\hline $\mathrm{AR} / \mathrm{CuSO}_{4}$ after heat pressing & 1727 & -8 & 1242 & -12 & 1158 & -5 \\
\hline
\end{tabular}

Abbreviations: AR, acrylate rubber; $\mathrm{CuSO}_{4}$ copper sulfate; IR, infrared

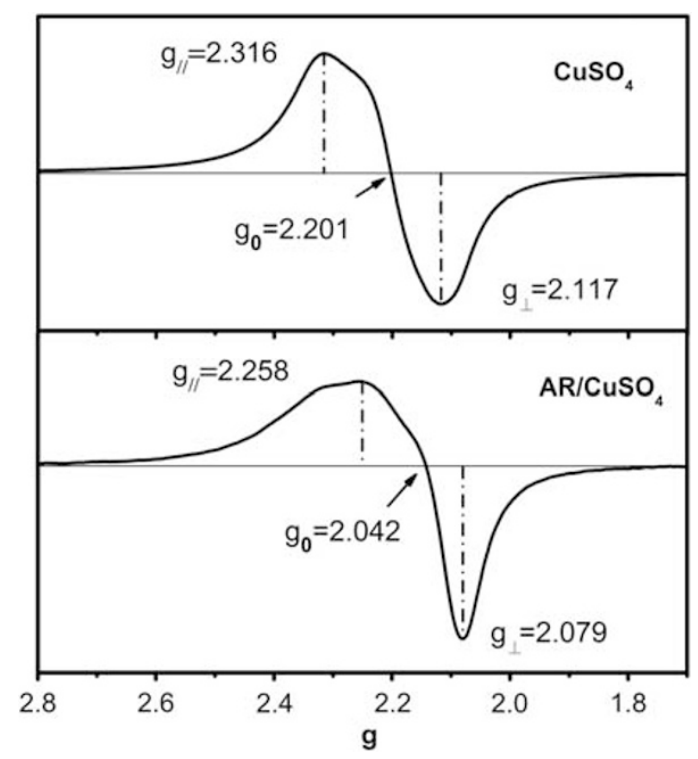

Figure 2 ESR spectra of $\mathrm{CuSO}_{4}$ and $\mathrm{AR} / \mathrm{CuSO}_{4}$ composite after heat pressing.
$>$ ester group of AR. Kivelson et $_{\text {al. }}{ }^{32}$ reported a $g_{\|}<2.3$ for a covalent character of the metal-ligand bond and $>2.3$ for an ionic character. By applying this criterion, the ionic character of the $\mathrm{Cu}^{2+}-\mathrm{SO}_{4}{ }^{2-}$ bond and the covalent character of the $\mathrm{Cu}^{2+}-\mathrm{COOR}$ bond in the complexes in this study can be predicted. $\mathrm{Cu}^{2+}$ preferred to form stable coordination bonds with $-\mathrm{COOR}$ as opposed to $\mathrm{SO}_{4}{ }^{2-}$.

The swelling behaviors of the vulcanizates reflect their crosslinking property. The swelling behaviors of the $\mathrm{AR} / \mathrm{CuSO}_{4}$ mixtures in a 6-month reserve and the hot-pressed $\mathrm{AR} / \mathrm{CuSO}_{4}$ composites in ethyl acetate were observed at room temperature and are presented in Figure 3. Incidentally, fresh $\mathrm{AR} / \mathrm{CuSO}_{4}$ mixtures were capable of being dissolved in ethyl acetate in a few hours. The swell index $(Q)$ of each sample reached a maximum when its crosslinking network extended as far as possible. The $Q$ values of the samples with very low crosslinking densities decreased gradually, whereas the samples with high crosslinking densities reached a swell equilibrium. These results were thought to be dependent on theinterfacial interactions between the $\mathrm{CuSO}_{4}$ particles and the polymer chains. As observed in Figure 3, an increase in the heat-pressed temperature or the $\mathrm{CuSO}_{4}$ content may subsequently increase the crosslinking density of the $\mathrm{AR} / \mathrm{CuSO}_{4}$ composites.

It can be concluded from the above results that, due to the electron-donating property of the guest (ester group) and the electron-receipting property of the host $\left(\mathrm{CuSO}_{4}\right)$, coordination interaction is established, and the linear rubber macromolecules are crosslinked into a three-dimensional network with $\mathrm{CuSO}_{4}$ particles as crosslinking points. A schematic diagram of the coordination of the crosslinked $\mathrm{AR} / \mathrm{CuSO}_{4}$ composites is shown in Figure 4.

\section{Coordination crosslinking reaction of $\mathrm{AR} / \mathrm{CuSO}_{4}$}

DMA was used to investigate the coordination reaction in an AR/ $\mathrm{CuSO}_{4}$ mixture. Figure 5 shows the variation in the storage modulus $\left(G^{\prime}\right)$ with the temperatures for raw $\mathrm{AR}$ and an $\mathrm{AR} / \mathrm{CuSO}_{4}$ mixture. $\mathrm{AR}$ has a suitable thermal stability. In the glass transition region $(0$ to $50{ }^{\circ} \mathrm{C}$ ), the value of $G^{\prime}$ of the AR decreased monotonously. $G^{\prime}$ of the $\mathrm{AR} / \mathrm{CuSO}_{4}$ mixture had the same decreasing tendency as it did in the beginning, whereas the degree to which it decreased became less (stage 1, Figure 5) in the temperature range from 25 to $50{ }^{\circ} \mathrm{C}$. The reason for this trend was that (1) the motion of the AR chain segments was restricted by severalof the coordination bonds between -COOR and $\mathrm{Cu}^{2+}$ that were generated during milling and storage. The value of $G^{\prime}$

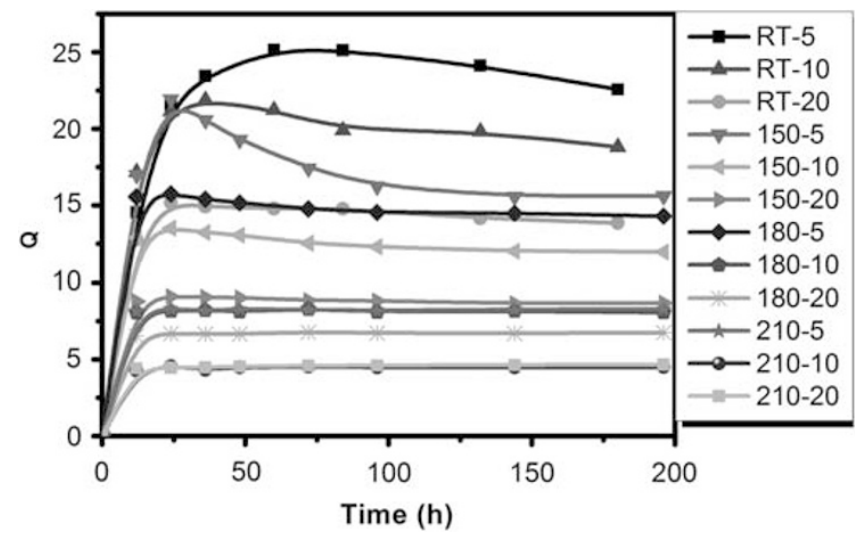

Figure 3 Swelling behaviors of $\mathrm{AR} / \mathrm{CuSO}_{4}$ composites with $\mathrm{CuSO}_{4}$ content of $5 \mathrm{phr}, 10 \mathrm{phr}$ and $20 \mathrm{phr}$ in reserve for 6 months at room temperature (noted by RT-5, RT-10, and RT-20, respectively) and after heat pressing at 150 , 180 and $210^{\circ} \mathrm{C}$ for 20 min (noted by $150-5,150-10,150-20,180-5$, etc.). A full color version of this figure is available at Polymer Journal online. 


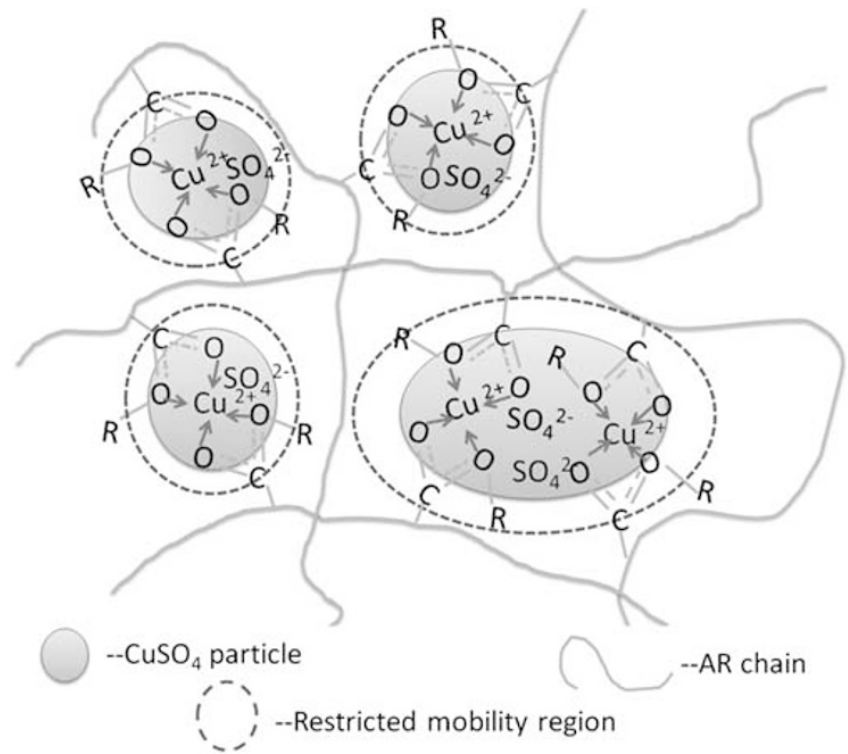

Figure 4 Schematic representation of the coordination bonded $\mathrm{AR} / \mathrm{CuSO}{ }_{4}$ networks. A full color version of this figure is available at Polymer Journal online.

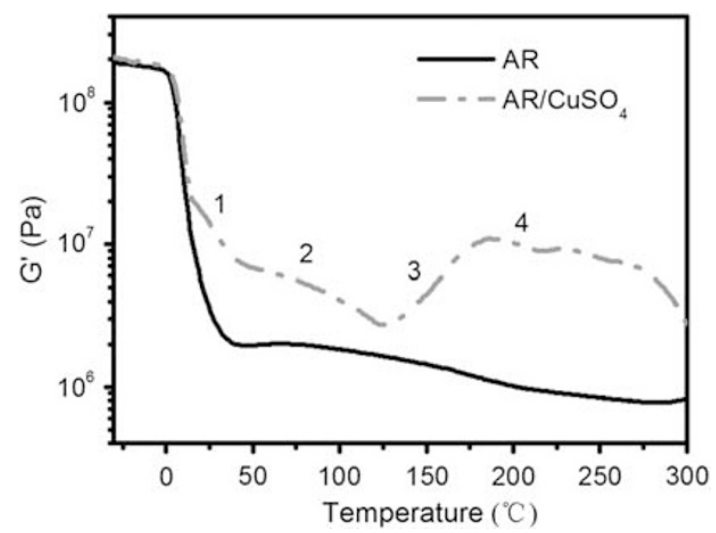

Figure 5 Dynamic mechanical properties of raw AR and $\mathrm{AR} / \mathrm{CuSO}_{4}(100 /$ 10) mixture as a function of temperature. A full color version of this figure is available at Polymer Journal online.

of the $\mathrm{AR} / \mathrm{CuSO}_{4}$ mixture showed a downward trend (stage 2, Figure 5) and visible augmentation (stage 3); meanwhile, the value of $G^{\prime}$ of the AR decreased slowly with temperature. The downward trend in $G^{\prime}$ of the $\mathrm{AR} / \mathrm{CuSO}_{4}$ mixture was attributed to (2) the melting of the $\mathrm{CuSO}_{4}$. The increasing trend (3) in $G^{\prime}$ was thought to be the result of the formation of three-dimensional networks. Generally, a compatible filler or an additive can result in stronger chain segment interactions in a polymer either via chemical reactions or through physical adsorption. In this case, the coordination crosslinking formed as a result of the $-\mathrm{COOR} \rightarrow \mathrm{Cu}^{2+}$ bonds according to FT-IR. When the heating temperature reached $200{ }^{\circ} \mathrm{C}$, the value of $G^{\prime}$ of the $\mathrm{AR} / \mathrm{CuSO}_{4}$ mixture stopped increasing (stage 4). The reason for this finding lies in the following aspects: the $\mathrm{CuSO}_{4}$ crystals melted, and the coordination reaction rate decreased with the concentration of unreacted COOR groups and $\mathrm{Cu}^{2+}$ ions.

It is known that the crosslinking behavior of rubber materials at a fixed temperature is important for the design and establishment of process conditions, such as temperature and time. Therefore, the crosslinking behavior of an $\mathrm{AR} / \mathrm{CuSO}_{4}$ compound under an

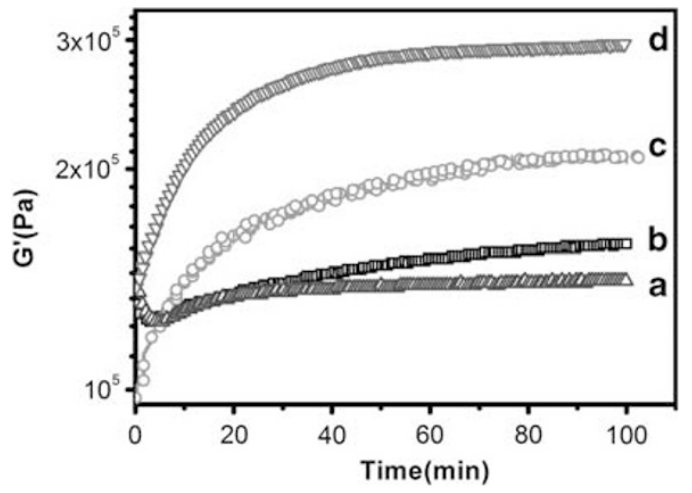

Figure 6 Dynamic mechanical properties of raw AR and AR/CuSO ${ }_{4}(100 /$ 10) mixtures as a function of time during isothermal processes: raw $A R$ at $180^{\circ} \mathrm{C} \mathrm{(a);} \mathrm{AR} / \mathrm{CuSO}_{4}$ mixture at $150^{\circ} \mathrm{C}$ (b), $180^{\circ} \mathrm{C}$ (c) and $210^{\circ} \mathrm{C}$ (d). $\mathrm{A}$ full color version of this figure is available at Polymer Journal online.
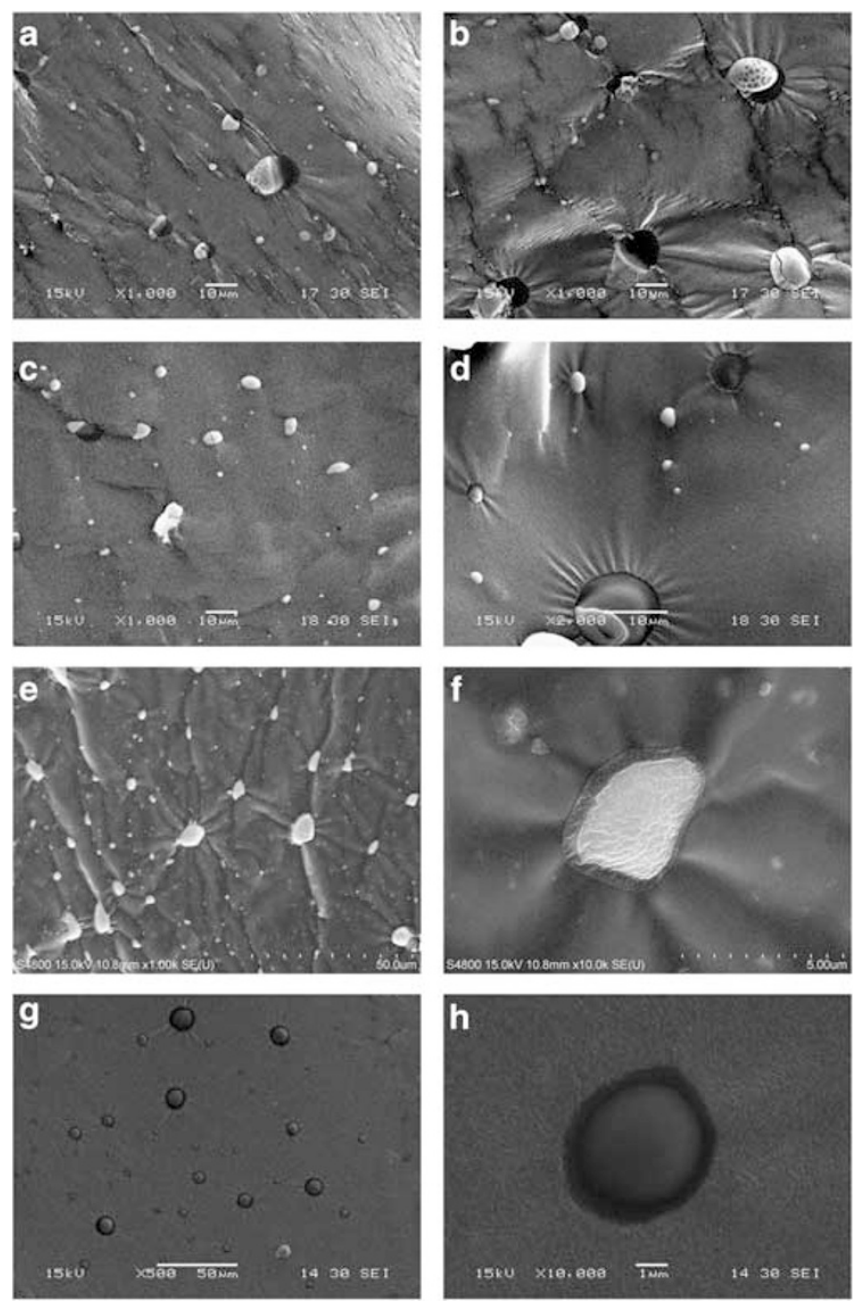

Figure 7 SEM images of $\mathrm{AR} / \mathrm{CuSO}_{4}$ (100/10) composites: (a, b) unheated; (c, d) after heat pressing at $150^{\circ} \mathrm{C} ; \mathbf{e}, \mathbf{f}$ after heat pressing at $180^{\circ} \mathrm{C} ;(\mathbf{g}, \mathbf{h})$ after heat pressing at $210^{\circ} \mathrm{C}$.

isothermal process was investigated by DMA (Figure 6). It was found that the value of $G^{\prime}$ of the raw $\mathrm{AR}$ at $180^{\circ} \mathrm{C}$ barely increased, whereas the value of $G^{\prime}$ of the $\mathrm{AR} / \mathrm{CuSO}_{4}$ compound obtained under designed temperatures increased significantly with the increase in time, and the 
resulting $G^{\prime}$ values increased with the rise in testing temperature. In addition, the value of $G^{\prime}$ of the $\mathrm{AR} / \mathrm{CuSO}_{4}$ compounds presented two outcomes: the initial value of $G^{\prime}$ increased rapidly and then smoothly. The concentration of the unreacted copper ions and the ester groups of the AR was initially high. The coordination reaction continued to occur as long as they encountered each other. The value of $G^{\prime}$ increased remarkably with the rapid formation of coordination networks. The motion of the chain segments then became increasingly difficult as a result of the restriction from the coordination crosslinking, as well as the decrease in the concentration of the unreacted function groups and the metal ions. Therefore, the coordination reaction rates declined gradually, leading to the smooth increase in the value of $G^{\prime}$. Furthermore, the optimal crosslinkingtime $\left(T_{o p}\right)$ under different temperatures could be determined by the differential curves. It was found that $T_{o p}$ was too long for $150^{\circ} \mathrm{C}$ and was $31 \mathrm{~min}$ and $20 \mathrm{~min}$, respectively, for 180 and $210^{\circ} \mathrm{C}$.

\section{Micromorphology}

The micromorphology of the cross section of the $\mathrm{AR} / \mathrm{CuSO}_{4}$ composites before and after heat pressing at different temperatures is shown in Figure 7. As observed in Figures $7 \mathrm{a}-\mathrm{d}$, small particles were embedded, whereas large particles were separated from the AR matrix. This phenomenon was attributed to the weak interactions between tAR and $\mathrm{CuSO}_{4}$ before heat pressing and after heat pressing at low temperatures $\left(150^{\circ} \mathrm{C}\right)$. In Figure $7 \mathrm{e}$, all of the $\mathrm{CuSO}_{4}$ particles were fixed in the AR matrix and surrounded by actinomorphous drapes after heat pressing at $180^{\circ} \mathrm{C}$. On the surface of the $\mathrm{CuSO}_{4}$ particle,

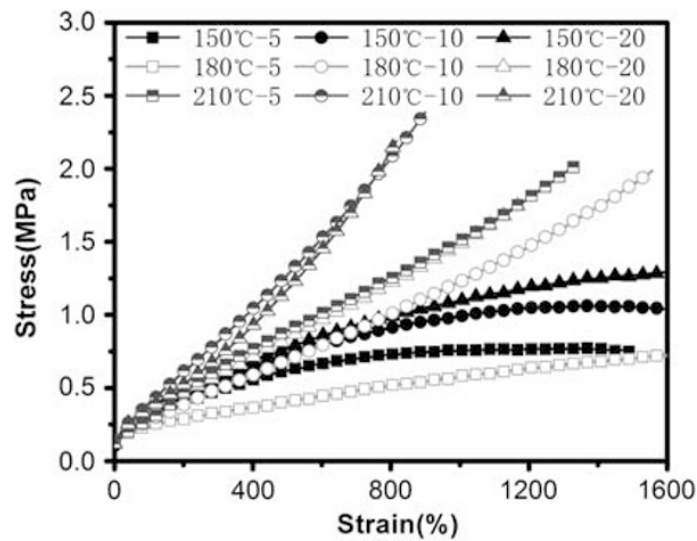

Figure 8 Strain-stress curves of $\mathrm{AR} / \mathrm{CuSO}_{4}$ composites with $\mathrm{CuSO}_{4}$ content of $5 \mathrm{phr}, 10 \mathrm{phr}$ and $20 \mathrm{phr}$ obtained after heat pressing at 150, 180 and $210^{\circ} \mathrm{C}$ for $20 \mathrm{~min}$. A full color version of this figure is available at Polymer Journal online. there was a thin sheet (approximately $500 \mathrm{~nm}$ in thickness) of $\mathrm{AR}$, as shown in Figure $7 f$. This finding indicated that strong interactions between the $\mathrm{CuSO}_{4}$ particles and the AR chains were obtained due to the coordination reaction during heat pressing. The AR chains were crosslinked with these $\mathrm{CuSO}_{4}$ particles as junctions. Moreover, for actinomorphous drapes, each $\mathrm{CuSO}_{4}$ particle was surrounded by a dark ring after heat pressing at $210^{\circ} \mathrm{C}$, as observed in Figures $7 \mathrm{~g}$ and $\mathrm{h}$. This dark ring likely originated from the thawing of water during crystallization. All of these particles were embedded in the AR matrix, which also indicated strong interactions and suitable compatibility.

\section{Mechanical property}

Figure 8 shows the tensile behaviors of $\mathrm{AR} / \mathrm{CuSO}_{4}$ composites with a $\mathrm{CuSO}_{4}$ content of $5 \mathrm{phr}$ (parts per hundreds of rubber), $10 \mathrm{phr}$ and $20 \mathrm{phr}$ obtained after heat pressing at various temperatures. The strain-stress behaviors can be divided into two categories according to their trends with large deformation: a slow increase and a fast increase. The strain-stress curves of the $\mathrm{AR} / \mathrm{CuSO}_{4}$ composites obtained after heat pressing at $150{ }^{\circ} \mathrm{C}$ had a slow-increase trend with increasing elongation. The tensile behaviors of the others were similar to traditional rubber, and the tensile strength rapidly increased with an increase in elongation. The adhesion strength at the interface determines the load transfer between the components. A strong interfacial bonding between the particles and the polymer matrix was critical for the effective stress transfer, leading to a high composite strength. When an external stress was applied, several AR chains were easily separated from the surfaces of the $\mathrm{CuSO}_{4}$ particles, as shown in Figures $7 \mathrm{a}$ and $\mathrm{b}$. These particles were incompetent as firm crosslinks due to their weak interactions with the AR. Following hightemperature heat pressing, the AR chains were coordination bonded to the surfaces of $\mathrm{CuSO}_{4}$ particles. When an external stress was applied, the motion of AR chains was limited by the $\mathrm{CuSO}_{4}$ particles as crosslinks developed and the load efficiently transferred between the $\mathrm{AR}$ chains and the $\mathrm{CuSO}_{4}$ particles. The $\mathrm{AR} / \mathrm{CuSO}_{4}$ composites showed pronounced reinforcement.

Furthermore, the $\mathrm{AR} / \mathrm{CuSO}_{4}$ composites displayed superior tensile properties with very high elongation at break. Several samples $\left(150{ }^{\circ} \mathrm{C}-10 \mathrm{~min}, 150^{\circ} \mathrm{C}-20 \mathrm{~min}, 180^{\circ} \mathrm{C}-5 \mathrm{~min}\right)$ did not break in the measuring range. It is known that the exchange reactions between metal ions and carboxylate groups are specific for carboxylated ionic thermoplastics, ionic blends and ionic elastomers during melting flow. ${ }^{33}$ In our case, the high elongation at break was also presumably related to the exchange reaction between $\mathrm{AR}$ and $\mathrm{Cu}^{2+}$, as shown in Figure 9. When an external force was applied, the molecular chains between the crosslinks $\left(\mathrm{CuSO}_{4}\right.$ particles and physical entanglement) were gradually stretched tight. When the stress was too large, several

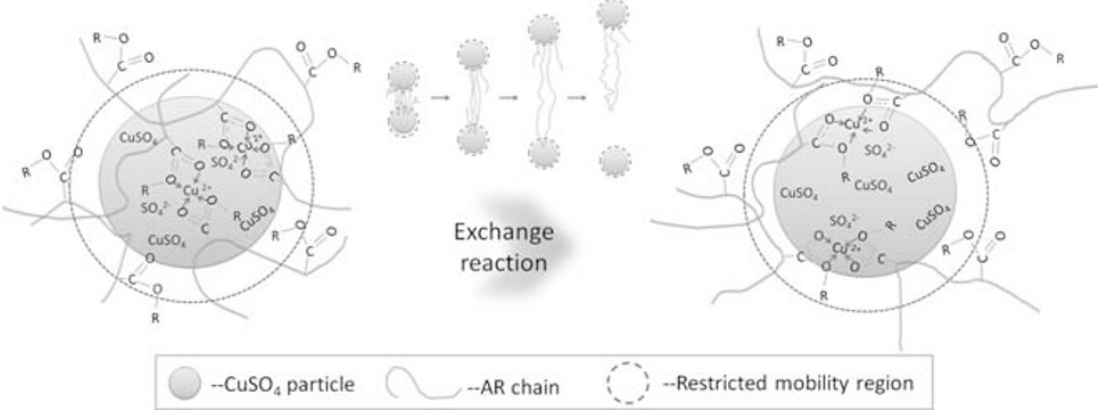

Figure 9 Schematic representation of the exchange reaction between AR and $\mathrm{CuSO}_{4}$ under external forces and a simplified mode of 'live crosslinks.' A full color version of this figure is available at Polymer Journal online. 
of the crosslinks decrosslinked as a consequence of the coordination bond dissociation. However, because the coordination reaction between $\mathrm{AR}$ and $\mathrm{CuSO}_{4}$ can be carried out at room temperature, the crosslinks were able to reform through an exchange reaction as if they were 'live'. These reformed crosslinks resumed their function of bearing high stress. In the center of Figure 9, a simplified mode of the 'live crosslinks' in an ideal status is shown; the crosslinks could slide along the polymer chain through an exchange reaction as a uniaxial tension was applied. The chain segments between these 'live crosslinks' would become longer unless no crosslinks were regenerated. Hence, the $\mathrm{AR} / \mathrm{CuSO}_{4}$ composites displayed superior deformation with a very high elongation at break. This characteristic is distinguishable from sulfur vulcanizates and ionomers.

\section{CONCLUSIONS}

With this work, we created a straightforward method to vulcanize AR through the coordination reactions between the ester groups of AR and $\mathrm{CuSO}_{4}$. The $\mathrm{AR} / \mathrm{CuSO}_{4}$ coordinate composites were prepared by simple mechanical blending and heat pressing. The results of FT-IR, ESR, equilibrium swelling and DMA demonstrated that coordinationbonded networks formed in the $\mathrm{AR} / \mathrm{CuSO}_{4}$ composites. The coordination reaction was capable of occurring at room temperature and was accelerated by increasing the temperature. SEM images showed that the AR chains bonded to the surface of $\mathrm{CuSO}_{4}$ in the $\mathrm{AR} / \mathrm{CuSO}_{4}$ composites. The extent of the crosslinking and the tensile properties of the $\mathrm{AR} / \mathrm{CuSO}_{4}$ composites increased with the $\mathrm{CuSO}_{4}$ load and the heat pressing temperature, which was determined by their swelling behaviors and their tensile behaviors. Theconsiderably high elongation at break was specific to the $\mathrm{AR} / \mathrm{CuSO}_{4}$ composites, which was presumably due to the exchange reactions between the ester groups of the AR and the copper ions.

\section{ACKNOWLEDGEMENTS}

We sincerely acknowledge the National Key Technology R \& D Program of China (2008BAC46B10), the opening fund (2010) of the Engineering Research Center of Biomass Materials, the Ministry of Education, Southwest University of Science and Technology, Mianyang, China and the University Student Renovation Project of China (101025122).

1 Calder, C. D. Halogenated polyacrylate elastomers. US 4069180, United States of America (1978).

2 De, M. R. \& Tucker, H. Acrylic ester vinylbenzyl chloride elastomers. US 3763119, United States of America (1973).

3 Yokota, A. \& Kano, T. Halogen-containing acrylic rubber composition and products of vulcanization thereof. JP20090172575, Japan (2009).

4 Fujita, M. \& Nakagawa, Y. Acrylic rubber composition. JP2000198901, Japan (2000).

5 Miyauchi, T. \& Abe, Y. Acrylic rubber composition, and vulcanized rubber thereof and its applications. JP20080012158, Japan (2008).

6 Masuda, H. \& Ishii, Y. Acrylic rubber, acrylic rubber composition, and acrylic rubber crosslinked product. JP 2008214418, Japan (2008).
7 Mathew, G., Rhee, J.M., Lee, Y.S., Park, D.H. \& Nah, C. Cure kinetics of ethylene acrylate rubber/clay nano-composites. J. Ind. Eng. Chem. 14, 60-65 (2008).

8 Miyauchi, T. \& Abe, Y. Acrylic rubber composition, vulcanized rubber obtained therefrom, and use thereof. WO2008JP59385, Japan (2008).

9 Ichikawa, M. \& Suzuki, A. Acrylic rubber composition and rubber hose obtained using the same. US19950454625, United States of America (1995).

10 Weisendanger, R. \& Reisinger, M UV-curable epoxy acrylates. CH20020002161, Switzerland (2002)

11 Berry, D. D., Critchfield, F. E., Gerkin, R. M., Koleske, J. V. \& Dunski, N. New comonomer for preparing high performance sulfur curable acrylic rubbers. Rubber World 170, 42-44, 46-47 (1974).

12 Da, J. L., Lanzavecchia, L. \& Savini, G. Vulcanizable compositions based on modified acrylic rubbers. US19950413893, United States of America (1995).

13 Mprris, R.E. \& Falls, C. Acrylate rubber vulcanizable compositions. US19730397991, United States of America (1973).

14 Soares, B. G., Santos, D. M. \& Sirqueira, A. S. A novel thermoplastic elastomer based on dynamically vulcanized polypropylene/acrylic rubber blends. Express Polym. Lett. 2, 602-613 (2008)

15 Morris, R. E. \& Falls, C. Acrylate rubber vulcanizable compositions. US19730398090, United States of America (1973).

16 Jablonski, D. E. Acrylate rubber compositions. US19820367209, United States of America (1982).

17 Giannetti, E., Mazzocchi, R., Fiore, L. \& Crespi, E. Ammonium salt catalyzed crosslinking mechanism of acrylic rubbers. Rubber Chem. Technol. 56, 21-30 (1983).

18 Hagiwara, S. \& Koga, M. Acrylic rubber composition. JP20050325586, Japan (2005).

19 Ooishi, T. \& Ishii, Y. Acrylic rubber composition and crosslinked product. JP20050160688, Japan (2005).

20 Schreiner, B. \& Beck, W. Coordination of the Ester group-hydrido-rhodium (III) and iridium (III) complexes of orthometallated diphenylmethylene glycine esters. Zeitschr Allge Chem 636, 499-505 (2010).

21 Leach, B. E. \& Angelici, R. J. Metal-ion catalysis of the hydrolysis of some amino acid ester N, N-diacetic acids. J. Am. Chem. Soc. 90, 2504-2508 (1968).

22 Kapoor, P., Pathak, A., Kaur, P., Venugopalan, P. \& Kapoor, R. Steric control of coordination: unusual coordination mode of dimethylpyridine-2,6-dicarboxylate in a new dinuclear copper(II) complex $\left[(\mathrm{dmpc})(\mathrm{Cl})(\mu-\mathrm{Cl}) \mathrm{Cu}_{2}(\mu-\mathrm{Cl})(\mathrm{Cl})(\mathrm{dmpc})\right]$ and reversal of the coordination mode in $\left[\mathrm{Cu}(\mathrm{dmpc})\left(\mathrm{H}_{2} \mathrm{O}\right)_{3}\right]\left(\mathrm{ClO}_{2}\right)_{2}$. Transition Met. Chem. 29, 251-258 (2004)

23 Fisher, J. W. \& Trinkle, K. L. Iodide dealkylation of benzyl, PMB, PNB, and t-butyl Nacyl amino acid esters via lithium ion coordination. Tetrahedron Lett. 35, 2505-2508 (1994).

24 Szabo, M. J., Szilagyi, R. K. \& Bencze, L. Density functional studies of [(alkoxycarbonyl) methyl] cobalt tricarbonyltriphenylphosphine complexes: an a-ester $\square$ 3-coordination. Inorg. Chim. Acta. 344, 158-168 (2003).

25 Rolker, J. \& Glasner, T. Modification of acrylate polymers by treatment with metal carbonyl. US 3959231, United States (1973).

26 Nunnery, G. A., Jacob, K. I. \& Tannenbaum, R. Physical gelation of cellulose acetate propionate solutions mediated by metal carbonyl complexes. Polymer 51, 1082-1087 (2010)

27 Nakamoto, K., Fujita, J., Tanaka, S. \& Kobayashi, M. Infrared spectra of metallic complexes. IV. comparison of the infrared spectra of unidentate and bidentate metallic complexes. J. Am. Chem. Soc. 79, 4904-4908 (1957).

28 Aubin, R. \& Rivest, R. Sur les réactions des polyesters avec le tétrachlorure de titane: I. La réaction de l'oxalate de diéthyle avec le tétrachlorure de titane. Can. J. Chem. 36, 915-920 (1958).

29 Hull, R. V., Li, L., Xing, Y.C. \& Chusuei, C. C. Pt nanoparticle binding on functionalized multiwalled carbon nanotubes. Chem. Mater. 18, 1780-1788 (2006).

30 Kneubuhl, F.K. Line shapes of electron paramagnetic resonance signals produced by powders, glasses, and viscous liquids. J. Chem. Phys. 33, 1074-1078 (1960).

$31 \mathrm{Lu}$, X.Q. \& Johnson, W.D. The reaction of aquatic humic substances with copper (II) ions: an ESR study of complexation. Sci. Total Environ. 203, 199-207 (1997).

32 Kivelson, D. \& Neiman, R. ESR Studies on the bonding in copper complexes. J. Chem. Phys. 35, 149-155 (1961).

33 Antonya, P. \& De, S. K. Ionic thermoplastic elastomers: a review. Polym. Rev. 41, 41-77 (2001). 